\title{
Macrofauna edáfica na ecológica na Estação Ecológica Curral do Meio, Caatinga Alagoana
}

\author{
Edaphic macrofauna in the Estação Ecológica Curral do Meio, Alagoana Caatinga
}

\author{
SANTOS ${ }^{1}$, G. R.; ARAUJO², K. D.; $\mathrm{SILVA}^{3}$, F. G.
} geovaniaricardo@hotmail.com

\begin{abstract}
Resumo
A macrofauna é um grupo de invertebrados responsáveis pela fragmentação e revolvimento da matéria orgânica do solo. O objetivo do trabalho foi avaliar a distribuição, abundância e riqueza da macrofauna edáfica em ambiente de Caatinga, na Estação Ecológica Curral do Meio, Semiárido de Alagoas. Foram selecionadas 40 pontos de coleta, avaliados entre Outubro de 2015 à Agosto de 2016. Os organismos > $2 \mathrm{~mm}$ foram capturados com armadilha Provid, foram quantificados e identificados. Foi aplicado o Índice de Diversidade de Shannon $(\mathrm{H})$ e pelo Índice de Equabilidade de Pielou $(e)$. Foram determinadas variáveis edafoclimáticas. O grupo taxonômico mais abundante é Hymenoptera, destacando-se também a ocorrência de Coleoptera e Araneae, comprovados pela menor diversidade e uniformidade; A maior riqueza dos grupos taxonômicos na área de pesquisa está associada à ampla cobertura vegetal de Caatinga; A abundância de indivíduos é maior e a riqueza de grupos e menor quando há temperaturas do solo elevadas e consequentemente menores umidade no solo.
\end{abstract}

Palavras-chave: Semiárido. Fauna do solo. Índices ecológicos. Função ecológica.

\begin{abstract}
The macrofauna is a group of invertebrates responsible for the fragmentation and reversal of organic matter in the soil. The objective of this work was to evaluate the distribution, abundance and richness of the edaphic macrofauna in the Caatinga environment, in the Estação Ecológica Curral do Meio, Semiarid of Alagoas. It was selected 40 collection points, evaluated from October 2015 to August 2016. The organisms > $2 \mathrm{~mm}$ were captured with Provid trap, were quantified and identified. The Shannon Diversity Index $(\mathrm{H})$ and the Pielou Equity Index (e) were applied. Edaphoclimatic variables were determined. The most abundant taxonomic group is Hymenoptera, highlighting also occurrence of Coleoptera and Araneae, evidenced by the smaller diversity and uniformity; The greatest richness of the taxonomic groups in the research area is associated to the wide vegetation cover of Caatinga; The abundance of individuals is greater and the richness is lower when there are high soil temperatures and consequently lower soil moisture.
\end{abstract}

Keywords: Semiarid. Soil Fauna. Ecological indexes. Ecological function.

\section{INTRODUÇÃO}

A variação nos padrões de distribuição e abundância da fauna do solo em ambientes tropicais pode ser diferente, notadamente em regiões com períodos de estiagem e chuvoso bem definido (ALMEIDA et al., 2013). Os organismos apresentam um sistema de adaptação, sobrevivendo à escassez hídrica e de alimento, além de temperaturas elevadas do solo, de maneira que a sua dinâmica está diretamente relacionada aos fatores edafoclimáticos, como temperatura e umidade do solo, carbono e matéria orgânica (OLIVEIRA e SOUTO, 2011).

De forma geral, os organismos da macrofauna são representados por diversos grupos de invertebrados existentes entre as várias camadas da serapilheira e do solo. A macrofauna é 
classificada com tamanho corporal $>2,0 \mathrm{~mm}$, dentre eles, Isoptera (Cupim), Hymenoptera (Formiga), Coleoptera (Besouro), Isopoda (Tatuzinho), Araneae (Aranha), Chilopoda (Centopeia), Diplopoda (Piolho-de-cobra), Blattodea (Barata), dentre outros. Esses organismos exercem funções de fragmentação, dispersão de sementes e revolvimento, nas propriedades físicas, químicas e biológicas do solo (PEREIRA et al., 2012).

Estes organismos são responsáveis pela construção de ninhos, cavidades, galerias e transporte de materiais, funções importantes ao solo, favorecendo a disponibilidade de recursos para outros organismos e produzindo estruturas biogênicas, que promovem a diversidade biológica de outros grupos tróficos (ALVES et al., 2014). As espécies invertebradas do solo apresentam grande sucesso evolutivo, sendo os grupos Hymenoptera e Coleoptera os mais abundantes de todos os nichos terrestres, isso se deve ao fato de o grupo Hymenoptera apresentar grande desenvolvimento nos ambientes de poucos recursos, já o grupo Coleoptera ocorre por suas caracteríticas morfologicas - estojo capaz de manter a umidade (MELO et al., 2009; MACHADO et al., 2008).

A relação dos macroinvetebrados com o solo promovem diversas funções ecológicas importantes no processo de qualidade do mesmo, de modo que, estas podem ser associadas a diversos processos na formação e estruturação física e química do solo, ciclagem de nutrientes, revolvimento do solo, incorporação de matéria orgânica, movimentam partículas, vertical e horizontalmente, formando agregados que aumentam a porosidade, aeração, infiltração e drenagem, e, consequentemente, podem desempenhar importantes funções nos processos ecológicos, como dispersão de sementes, predação, herbivoria, proteção de plantas contra herbívoros, além da sua interação com diversos grupos de organismos (MELO et al., 2009).

Dionísio et al. (2016) classificam os organismos em dois grupos, a fauna subterrânea e a de superfície. A fauna subterrânea habita no horizonte A e raramente vem à superfície do solo, apresentam movimentação e visão restritas, sensibilidades química e mecânica muito desenvolvida, fotofobia, corpo despigmentado, defesa pela produção de toxinas, resistência ao gás carbônico e, além disso, é pouco afetada pelos eventos microclimáticos e pelo manejo da superfície do solo, destacando-se algumas famílias do grupo Coleoptera e Isoptera.

Já a fauna de superfície habita o horizonte $O$ (orgânico) e vive sob resíduos orgânicos, movimenta-se com agilidade, apresenta acuidade visual, sensores desenvolvidos e corpo pigmentado, sendo afetada pela cobertura vegetal e pelas práticas culturais. Pode penetrar no solo pelas rachaduras ou cavidades naturais. As espécies alimentam-se de sementes ou plantas na região do colo ou da coroa e, algumas vezes, da parte aérea, como os grupos Hymeoptera, Diplopoda e Hemiptera (DIONÍSIO et al., 2016). 
A análise da diversidade das espécies ou de grupos (riqueza) e a abundância relativa (equabilidade) permitem avaliar os ambientes de Caatinga, sendo uma ferramenta para o conhecimento da complexidade e funcionalidade ecológica na dinâmica solo/planta em diferentes ações de manejo e como indicador de recuperação de áreas degradadas (ALMEIDA et al., 2013). Diante do exposto, objetivou-se avaliar a riqueza, equabilidade e diversidade da macrofauna edáfica como função ecológica em remanescente de Caatinga, na Estação Ecológica Curral do Meio, Alagoas.

\section{METODOLOGIA}

2.1 Caracterização dos municípios estudados

A pesquisa foi executada no município de Santana do Ipanema-Alagoas, localizada na Microrregião Geográfica de Santana do Ipanema e Mesorregião Geográfica do Sertão Alagoano (Figura 1). A Sede do município está localizado nas coordenadas geográficas $09^{\circ} 22^{\prime} 42^{\prime \prime} \mathrm{S}$ e $37^{\circ} 14^{\prime} 43^{\prime \prime} \mathrm{W}$, na altitude de $250 \mathrm{~m}$ (GOVERNO DO ESTADO DE ALAGOAS, 2011).

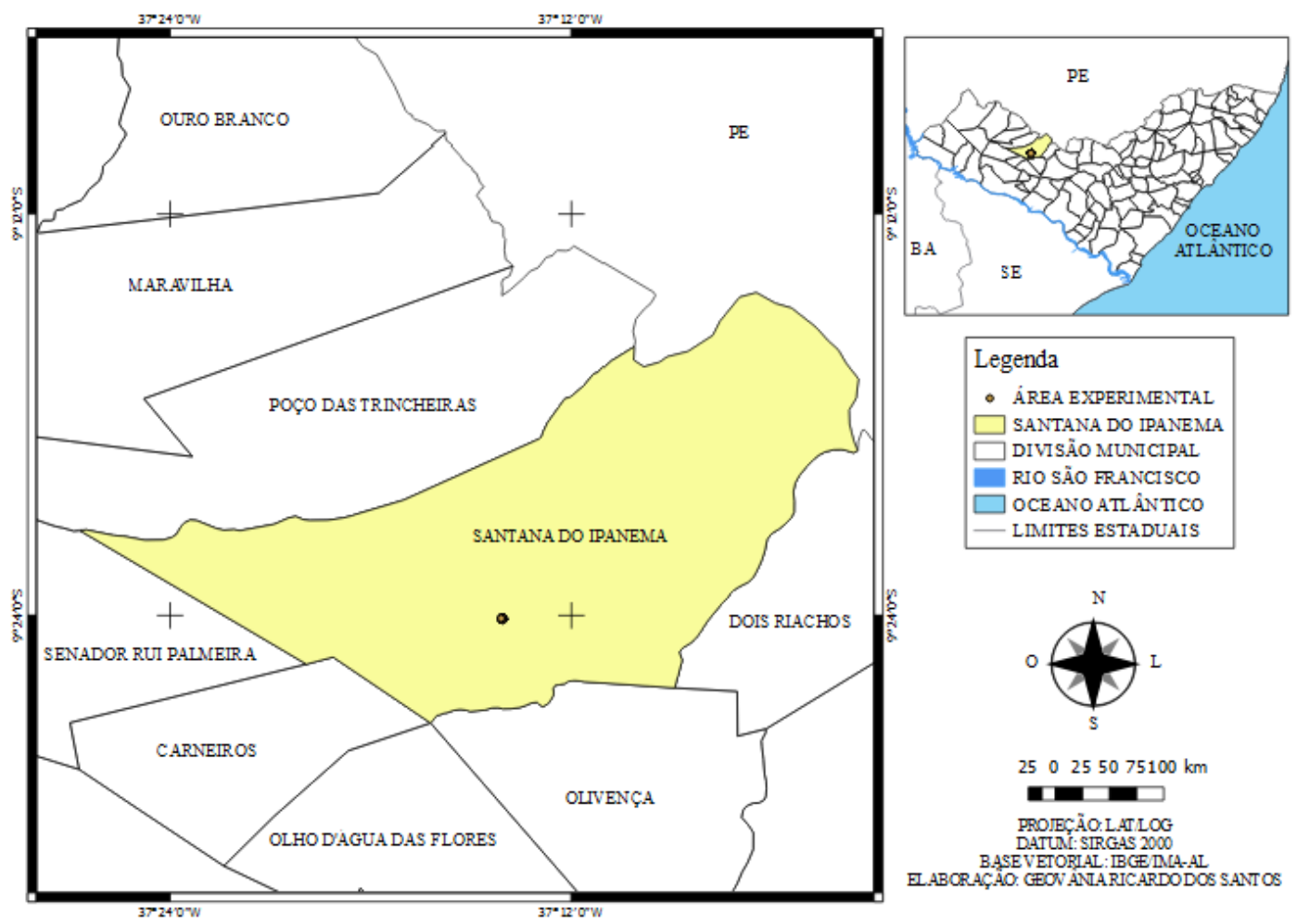

Figura 1. Localização do município de Santana do Ipanema, Alagoas.

A unidade geomorfológica está inserida na superfície de pediplanação e o clima da região está sob o domínio climático BSh-Tropical Semiárido, segundo a classificação de Köppen e 
bioclima 3bTh - com índice xerotérmico de 100 e 150, com 5 a 6 meses secos, de acordo com Gaussen.. O município é drenado pelo rio Ipanema na direção norte-sul para a calha do rio São Francisco (EMBRAPA, 2012).

Os solos predominantes são Argissolos Vermelho, formados a partir de rochas cristalinas, menos ácidas do que granitos, como granodioritos e similares, ocorrendo associados com pedregosidade e cascalhos, Neossolo Regolítico, pouco profundo, geralmente com cores claras ou esbranquiçadas, apresentando textura dominante na faixa de arenosa a média (franco-arenosa), Neossolos Litólico, rasos, ocupando grandes extensões no ambiente Semiárido onde é comum a presença de pedregosidade e/ou rochosidade e Planossolos Háplico, solos minerais imperfeitamente drenados, apresentando argila de atividade alta, ocorrendo em ambientes com restrições de drenagem (EMBRAPA, 2014; EMPRAPA, 2012).

A vegetação predominante da região é Caatinga hipoxerófila, com grau de xerofitismo menos acentuado (JACOMINE et al., 1975; AB'SABER, 2003).

\section{2 Área experimental}

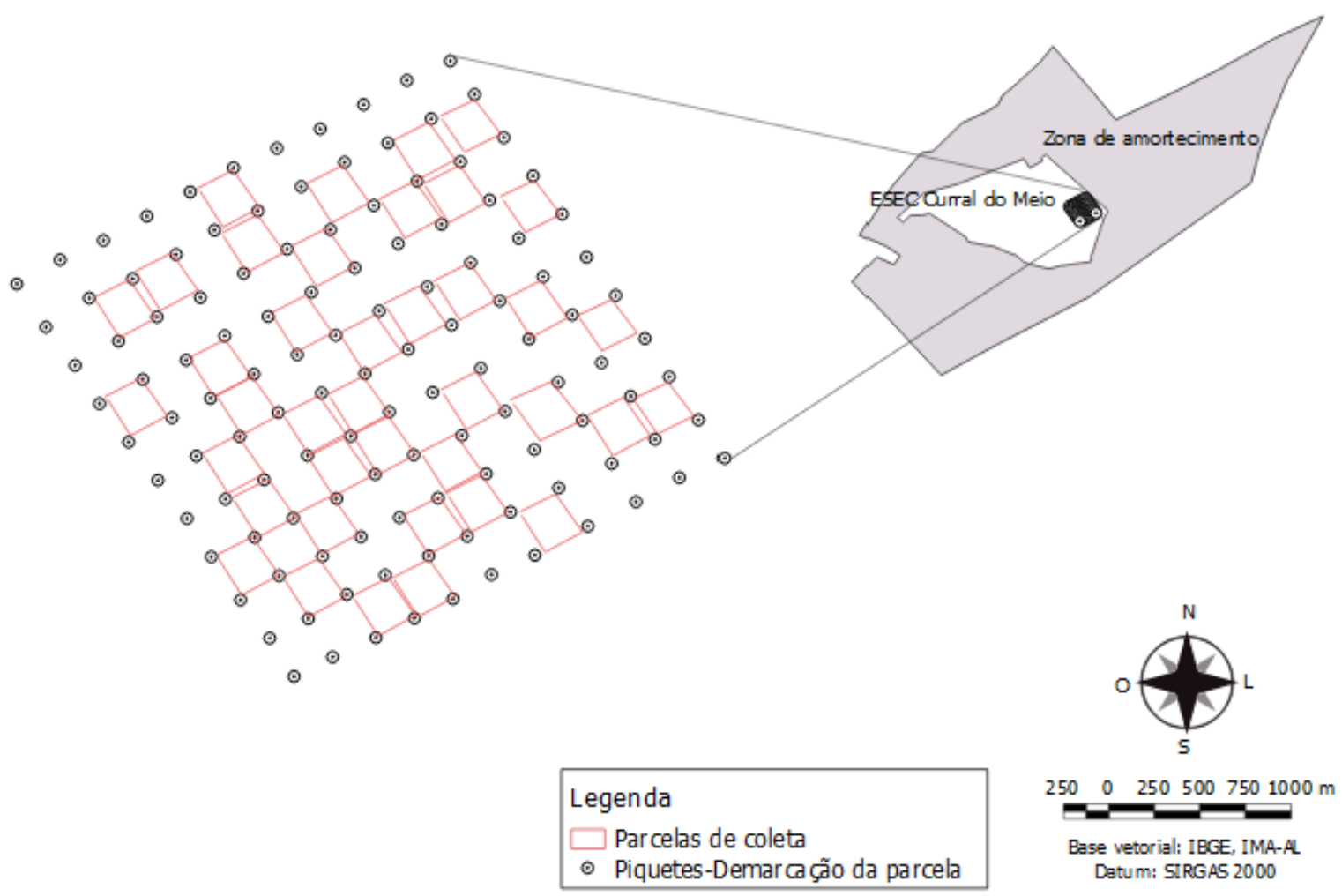

Figura 2. Localização da Estação Ecológica Curral do Meio, no município de Santana do Ipanema, Alagoas. 
A área da pesquisa está localizada na Estação Ecológica Curral do Meio (ESEC Curral do Meio) (Figura 2), em Santana do Ipanema-Alagoas, em um fragmento, remanescente de Caatinga Arbórea de 25 ha, com caracterítica de hipoxerómorfismo, em processo de restauração. A área que compreende o componente arbóreo-arbustivo da Caatinga está sob cuidados do Instituto do Meio Ambiente de Alagoas (IMA-Alagoas).

Neste fragmento florestal foi selecionado e delimitado uma área de 1 ha com piquetes de madeira, em seguida foram escolhidos previamente 40 pontos de coleta com ampla distribuição na área amostral para a avaliação dos organismos da macrofauna do solo.

As coletas ocorreram bimestralmente, de Outubro de 2015 à Agosto de 2016. Foram realizadas coletas de amostras de solo, para determinação do conteúdo de água e dos teores de carbono e matéria orgânica do solo. Também foram realizadas medidas da temperatura do solo e obtidos dados de precipitação pluvial.

\subsection{Avaliação da Macrofauna do solo}

A captura dos organismos da macrofauna edáfica foi realizada por meio de armadilhas Provid, confeccionadas com garrafas PET com capacidade $2 \mathrm{~L}$, com quatro aberturas de $2 \times 2 \mathrm{~cm}$, a partir da altura de $10 \mathrm{~cm}$ da base, contendo $200 \mathrm{~mL}$ de solução de detergente na concentração de $5 \%$ e 5 gotas de Formol P.A., as quais foram enterradas no nível do solo, permanecendo no campo por 96 horas (FORNAZIER et al., 2007).

Após o tempo de permanência no campo, as armadilhas foram recolhidas e o material foi passado em peneiras com malha de $0,25 \mathrm{~mm}$. Os organismos com comprimento maior que 2,0 $\mathrm{mm}$ foram armazenados em recipientes plásticos contendo álcool etílico 70\% (SWIFT et al., 1979). Em seguida, foram contados e identificados com auxílio de lupas, pinças, placas de petri, de acordo com a classe e ordem e/ou grupo taxonômico, utilizando a chave de identificação proposta por Triplehorn e Jonnson (2011).

\subsection{Aplicação dos índices ecológicos}

Os organismos da macrofauna do solo foram avaliados quantitativamente pela abundância de espécimes (BEGON et al., 1996).

Para a análise qualitativa dos organismos da macrofauna foram aplicados o Índice de Diversidade de Shannon $(\mathrm{H})$ e o Índice de Equabilidade de Pielou (e), onde a diversidade de espécies está associada a uma relação entre o número de espécies (riqueza de espécies) e a 
distribuição do número de indivíduos entre as espécies (equabilidade) (ODUM e BARRETT, 2008; BEGON et al., 1996).

O Índice de Diversidade de Shannon $(\mathrm{H})$ foi definido pela equação: $H=-\Sigma$ pi.log pi, em que: pi $=$ ni/N; ni $=$ Densidade de cada grupo; $\mathrm{N}=\Sigma$ da densidade de todas os grupos. $\mathrm{O}$ índice assume valores que variam de 0 a 5, sendo que os menores valores representam uma maior dominância de grupos em detrimento a outros.

$\mathrm{O}$ Índice de Equabilidade de Pielou ( $e$ ) foi definido por: $e=\mathrm{H} / \log \mathrm{S}$, em que: $\mathrm{H}=$ Índice de Diversidade de Shannon; $\mathrm{S}=$ Número de espécies ou grupos. O índice de Pielou $(e)$ é complementar ao de Shannon $(\mathrm{H})$, cuja redução dos valores indica que para um determinado grupo, não há boa distribuição (BEGON et al., 1996).

\subsection{Determinações do conteúdo de água do solo}

A preparação das amostras ocorreu conforme a norma ABNT-NBR 6457/2016. As amostras de solo foram coletadas, $30 \mathrm{~g}$ em cada lata de alumínio, onde foram previamente identificadas e pesadas individualmente. As latas com as amostras de solo úmido foram pesadas e levadas à estufa padrão com temperatura de $105{ }^{\circ} \mathrm{C}$, até alcançar peso constante, por um período de 24 horas. Em seguida, foram transferidas para um dessecador até atingirem temperatura ambiente e novamente as latas com as amostras de solo secas foram pesadas. A determinação do conteúdo de água do solo (\%) foi obtida pela equação: CAS\% = Pu-Ps/Psx100, em que: CAS = Conteúdo de água do solo (\%); Pu = Peso do solo úmido (g); Ps = Peso do solo seco (g) (TEDESCO et al., 1995).

2.6 Determinações dos teores de carbono e matéria orgânica do solo

A preparação preliminar das amostras de solo foi utilizada a norma ABNT-NBR 6457/2016. Foram coletadas amostras de solo, as quais foram acondicionadas em sacos plásticos etiquetados e posteriormente submetidos a secagem à sombra e ao ar, destorroadas, passadas em peneiras de malha $2 \mathrm{~mm}$ e maceradas. Em seguida, foram levadas para análise à Laboratório para análise e determinação dos teores de carbono (C) e matéria orgânica do solo (MO), em g Kg-1.

Seguindo o método colorimétrico de acordo com a metodologia da Embrapa (2009) que se baseia na leitura colorimétrica da cor verde do íon Cr (III) reduzido pelo carbono orgânico, utilizouse o dicromato de sódio decorrente da maior solubilidade, sendo a oxidação da matéria orgânica feita a frio, apenas agitando o solo em uma solução contendo dicromato de sódio e ácido sulfúrico por 10 minutos. Após repouso de uma hora foi adicionado em cada erlenmayer $50 \mathrm{~mL}$ de água 
destilada para promover a mistura das soluções. Em seguida, os erlenmayers contendo as amostras com as soluções foram acondicionados em bandejas e permaneceram durante 12 horas em decantação e as leituras de cada amostra foram realizadas no espectrofotômetro.

O carbono orgânico (C) e matéria orgânica (MO) do solo foi dado pela equação proposta por Raij et al., (2001) e Quaggio et al., (1979):

$\mathrm{ABS}=2-\log (\% \mathrm{~T}) ; \mathrm{CO}=0,0118+1,5483 \mathrm{xABS} ; \mathrm{CO}=0,0118+1,5483 \times \mathrm{ABSx}(60 / 1 \mathrm{~g}) ;$ $\mathrm{CO}=1,1241+2,2465 \mathrm{xCO}$, em que: $\mathrm{ABS}=$ Leitura da amostra; $\mathrm{CO}=\mathrm{Carbono}$ orgânico $\left(\mathrm{g} \mathrm{kg}^{-1}\right)$.

$\mathrm{MO}=\mathrm{COx} 1,724$, em que: $\mathrm{MO}=$ Matéria orgânica $\left(\mathrm{g} \mathrm{kg}^{-1}\right) ; \mathrm{CO}=$ Carbono orgânico $\left(\mathrm{g} \mathrm{kg}^{-1}\right)$; 1,724 = Fator utilizado por se admitir que na composição média do húmus, o carbono participa com $58 \%$.

2.7 Medições da temperatura do solo e precipitação pluvial

Foram realizadas medidas de temperatura do solo, por meio de termômetro digital espeto, na profundidade de 0-10 $\mathrm{cm}$. Também foram obtidos dados de precipitação pluvial por meio de pluviômetro Ville de Paris, instalado próximo à área experimental, para relacionar com as variáveis da pesquisa.

\subsection{Análise estatística}

Todos os dados foram trabalhados em softwares de livre acesso. A macrofauna do solo, carbono e matéria orgânica foram analisados por meio da estatística descritiva, utilizando-se o software Calc - Library Office. O diagrama de dispersão foi elaborado no programa R. A análise de agrupamento dos organismos foi realizada no Past 3.14, pelo método de distância euclidiana. Os valores de conteúdo de água do solo foram submetidos à análise de variância e as médias comparadas pelo teste de Tukey a $1 \%$ de probabilidade, pelo software Assistat 7.0 Beta.

\section{RESULTADOS E DISCUSSÃO}

3.1 Agrupamento das ordens da macrofauna do solo

A caraterização do arranjo interno da comunidade da macrofauna edáfica permitiu observar dois arranjos principais em função da frequência desses grupos nos pontos de amostragem (Figura $3)$. 
A análise de agrupamento evidenciou maior similaridade entre os grupos taxonômicos Coleoptera + Larva, Araneae, Hymenoptera + Larva e Diplopoda, significando maior relação de ligação em comparação aos demais grupos taxonômicos no dendograma (Figura 3).

Outros grupos taxonômicos também demostraram-se relacionados entre si, como Dermaptera, Diplura e Thysanoptera, Embioptera e Neuroptera (Larva), decorrente do baixo número de indivíduos nos pontos de coleta (Figura 3). Rovedder et al. (2004) destacam que a análise de agrupamentos é uma ferramenta que permite visualizar a distância de ligação (ou similaridade) entre as ordens de maior expressividade.

O coeficiente de correlação de Pearson (p) dos dados apresentou elevada relação ( $\mathrm{p}=0,9554)$, indicando que os resultados da análise de cluster foi altamente significativo. Os valores de significância de acordo com Begon et al. (1996) expressam que quando o p>1 há confiabilidade do resultado e quando o $\mathrm{p}<0$ a relação é fraca.

As correlações mais fortes indicam um reflexo da grande fragmentação vegetacional, concentrando principalmente as espécies mais frágeis em manchas e unidades de conservação, por outro lado, aquelas que não seguiram o padrão podem refletir em diferenças de habitat ou na densidade de espécies relacionadas a particularidades do ambiente (LIMA et al., 2015).

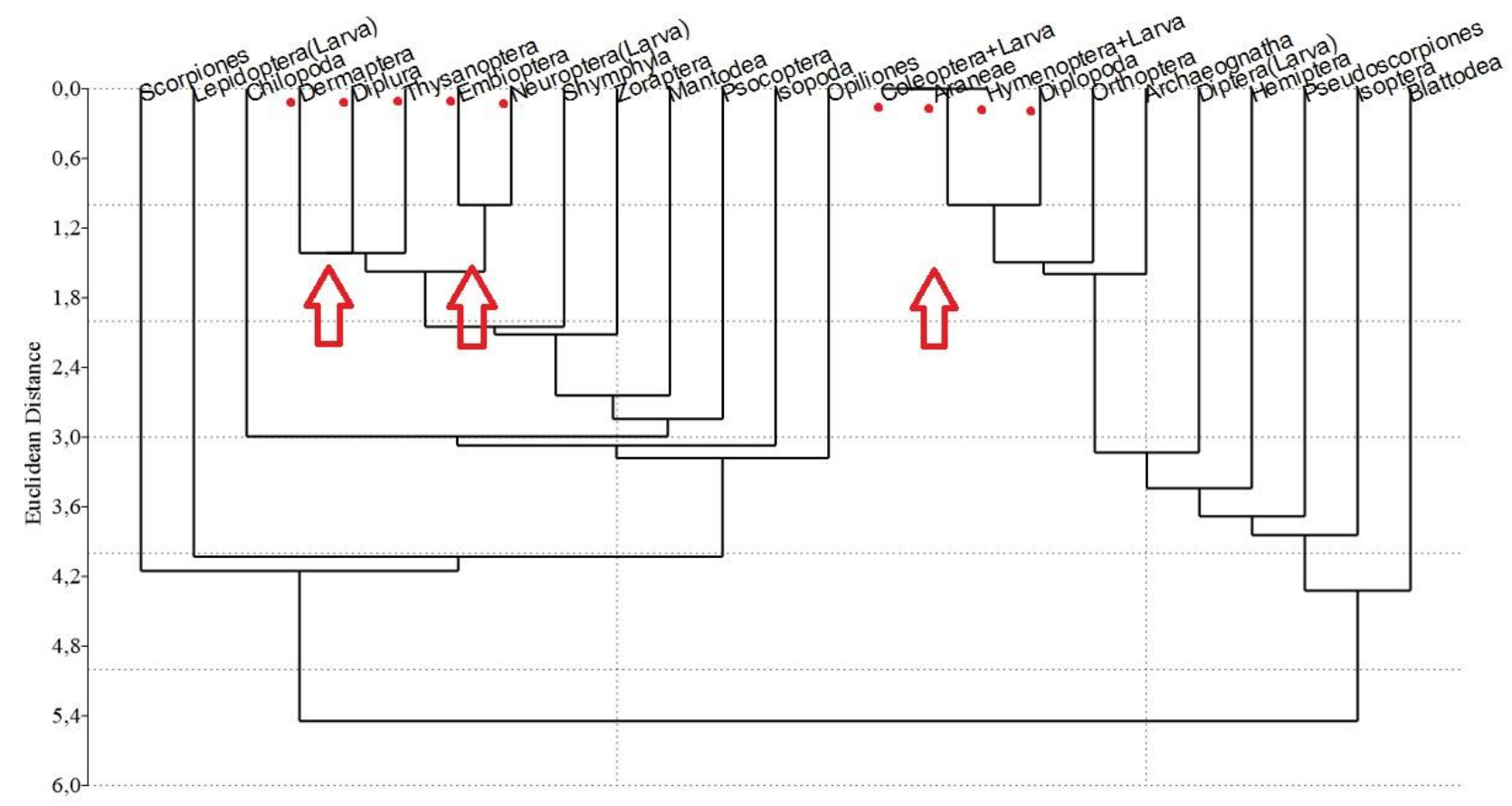

Figura 3. Dendrograma de agrupamento pelo método euclidiano para os organismos da macrofauna do solo. 


\subsection{Abundância e riqueza}

Nas parcelas experimentais, foram contabilizados 27.151 indivíduos, distribuídos em 25 grupos taxonômicos (Tabela 1), demostrando que a área apresenta uma quantidade e variedade faunística considerável, comparado com outros ambientes de Caatinga, em relação à abundância e riqueza de grupos faunísticos, conforme destacado na pesquisa de Pinheiro et al. (2014) em área de Caatinga no Ceará, que detectaram 847 indivíduos, distribuídos em 27 táxons no período chuvoso e de estiagem.

Baseado nos resultados da pesquisa, é possível verificar que mesmo os ambientes de Caatinga contendo particularidades, estes vão apresentar valores amostrais distintos, em virtude da heterogeneidade dos habitas. Nota-se essa assertiva a partir de outros dados coletados na Caatinga de outros Estados: Em área de Caatinga da Paraíba, Damasceno e Souto (2014) contabilizaram 12 grupos taxonômicos por um período de 12 meses. Em área de Caatinga preservada da Paraíba Almeida et al. (2015) quantificaram 6.402 indivíduos pertencentes a 18 grupos taxonômicos por um período de 12 meses. Estes são os padrões mais marcantes nas regiões de clima tropical com estações bem definidas, uma seca ou de estiagem, e outra úmida ou chuvosa, poucos grupos com muitos espécimes e muitos grupos com poucos espécimes, de acordo com Silva et al. (2012).

O grupo taxonômico mais abundante foi Hymenoptera (23.243 ind.; 85,61\%), outros grupos se destacaram, embora em menor percentual, como Coleoptera (1.652 ind.; 6,08\%) e Araneae (1.032 ind.; 3,80\%) (Tabela 1). Isso ocorreu pelo fato destes grupos serem os mais nos nichos terrestres (MACHADO et al., 2008). Cruz et al. (2015) avaliando a reserva florestal de Lagoa Seca, na Paraíba detectaram abundância para os grupos Hymenoptera $(53,04 \%)$ e Coleoptera $(16,49 \%)$. Gullan e Granston (2007) mencionam que a diversidade ou abundância numérica de certos grupos ou espécies é um indicador do sucesso desses organismos no ambiente.

Tabela 1. Número de indivíduos (NI) e percentual (\%) dos grupos taxonômicos da macrofauna do solo

\begin{tabular}{lcrr}
\hline Grupos taxonômicos & Nomes populares & NI & $\%$ \\
\hline Hymenoptera + Larva de & Abelha/Formiga/Vespa & $23.242+1$ & 85,61 \\
Hymenoptera & Besouro/Broca & $1.601+51$ & 6,08 \\
Coleoptera + Larva de Coleoptera & Aranha & 1.032 & 3,80 \\
Araneae & Traças-saltadoras & 253 & 0,93 \\
Archaeognatha & Piolho-de-cobra & 238 & 0,88 \\
Diplopoda & Garfanhoto/Esperança/Grilo & 201 & 0,74 \\
Orthoptera & Larva de Mosca/Larva de Mosquito & 158 & 0,58 \\
Diptera (Larva) & Cigarrinha/Percevejo/Pulgões/Soldadinho & 72 & 0,27 \\
Hemiptera & &
\end{tabular}




\begin{tabular}{lcrr} 
Pseudoscorpiones & Pseudoescorpião & 66 & 0,24 \\
Isoptera & Cupim & 63 & 0,23 \\
Blattodea & Barata & 51 & 0,19 \\
Isopoda & Tatuzinho-do-Solo & 31 & 0,11 \\
Lepidoptera (Larva) & Larva de Borboleta/Larva de Mariposa & 26 & 0,10 \\
Scorpiones & Escorpião & 20 & 0,07 \\
Chilopoda & Centopeia/Lacraia & 10 & 0,04 \\
Mantodea & Louva-deus & 8 & 0,03 \\
Psocoptera & Psocoptero/Piolho-de-livro & 8 & 0,03 \\
Opiliones & Aranha-Bode/Aranha-Fedorenta/Bodum & 7 & 0,03 \\
Shymphyla & Sinfilo & 3 & 0,01 \\
Zoraptera & Zoraptero & 3 & 0,01 \\
Embioptera & Embioptero & 2 & 0,01 \\
Dermaptera & Tesourinha & 1 & 0,00 \\
Diplura & Dipluro & 1 & 0,00 \\
Neuroptera (Larva) & Larva de Neuroptero & 1 & 0,00 \\
Thysanoptera & Trips/Lacerdinha & 1 & 0,00 \\
\hline Total & & 27.151 & 100,00 \\
\hline
\end{tabular}

Os grupos Hymenoptera, Coleoptera, Araneae e Diplopoda apresentaram ampla distribuição na área de pesquisa, sendo registrados nas 40 parcelas experimentais, cujos valores de frequência absoluta e relativa foram de 100 e 8,95\%, respectivamente (Tabela 2). Os grupos menos expressivos foram: Dermaptera, Diplura, Neuroptera (Larva) e Archaeognatha, com ocorrência de apenas 1 indivíduo (Tabela 2). Souza et al. (2015) e Vargas et al. (2013) reforçam a importância dos organismos edáficos como biondicadores de qualidade do solo, pois estes são afetados por diversos fatores, influenciando negativamente na abundância e sobrevivência de grupos específicos.

Tabela 2. Número de indivíduos (NI), número de parcelas de ocorrência (NP), frequência absoluta (FA) e frequência relativa (FR), dos organismos da macrofauna do solo

\begin{tabular}{lrrrr}
\hline Grupos taxonômicos & NI & NP & FA (\%) & FR (\%) \\
\hline Hymenoptera + Larva de Hymenoptera & $23.242+1$ & 40 & 100,00 & 8,95 \\
Coleoptera + Larva de Coleoptera & $1.601+51$ & 40 & 100,00 & 8,95 \\
Araneae & 1.032 & 40 & 100,00 & 8,95 \\
Archaeognatha & 253 & 38 & 95,00 & 8,50 \\
Diplopoda & 238 & 40 & 100,00 & 8,95 \\
Orthoptera & 201 & 38 & 95,00 & 8,50 \\
Diptera (Larva) & 158 & 31 & 77,50 & 6,94 \\
Hemiptera & 72 & 29 & 72,50 & 6,49 \\
Pseudoscorpiones & 66 & 28 & 70,00 & 6,26 \\
Isoptera & 63 & 26 & 65,00 & 5,82 \\
Blattodea & 51 & 21 & 52,50 & 4,70
\end{tabular}




\begin{tabular}{lrrrr} 
Isopoda & 31 & 8 & 20,00 & 1,79 \\
Lepidoptera (Larva) & 26 & 15 & 37,50 & 3,36 \\
Scorpiones & 20 & 15 & 37,50 & 3,36 \\
Chilopoda & 10 & 7 & 17,50 & 1,57 \\
Mantodea & 8 & 7 & 17,50 & 1,57 \\
Psocoptera & 8 & 7 & 17,50 & 1,57 \\
Opiliones & 7 & 5 & 12,50 & 1,12 \\
Shymphyla & 3 & 3 & 7,50 & 0,67 \\
Zoraptera & 3 & 3 & 7,50 & 0,67 \\
Embioptera & 2 & 2 & 5,00 & 0,45 \\
Dermaptera & 1 & 1 & 2,50 & 0,22 \\
Diplura & 1 & 1 & 2,50 & 0,22 \\
Neuroptera (Larva) & 1 & 1 & 2,50 & 0,22 \\
Thysanoptera & 1 & 1 & 2,50 & 0,22 \\
\hline Total & 27.151 & 40 & $1.117,50$ & 100,00 \\
\hline
\end{tabular}

No diagrama de dispersão há uma relação da distribuição da riqueza de organismos e a área amostral (Figura 4). As variáveis apresentaram correlação positiva, indicando que na medida em que aumenta a área (m) amostral, a riqueza de grupos também tende a aumentar (Figura 4). Nas parcelas iniciais nota-se uma considerável riqueza, isso se deve a ampla cobertura vegetal das espécies da Caatinga. Já nas áreas intermediárias que coincidiram com os pontos de coleta da macrofauna edáfica, observa-se uma redução na riqueza de grupos, em virtude dos mesmos encontrarem-se com cobertura vegetal mais aberta, forçando os organismos a migrarem para ambientes mais favoráveis.

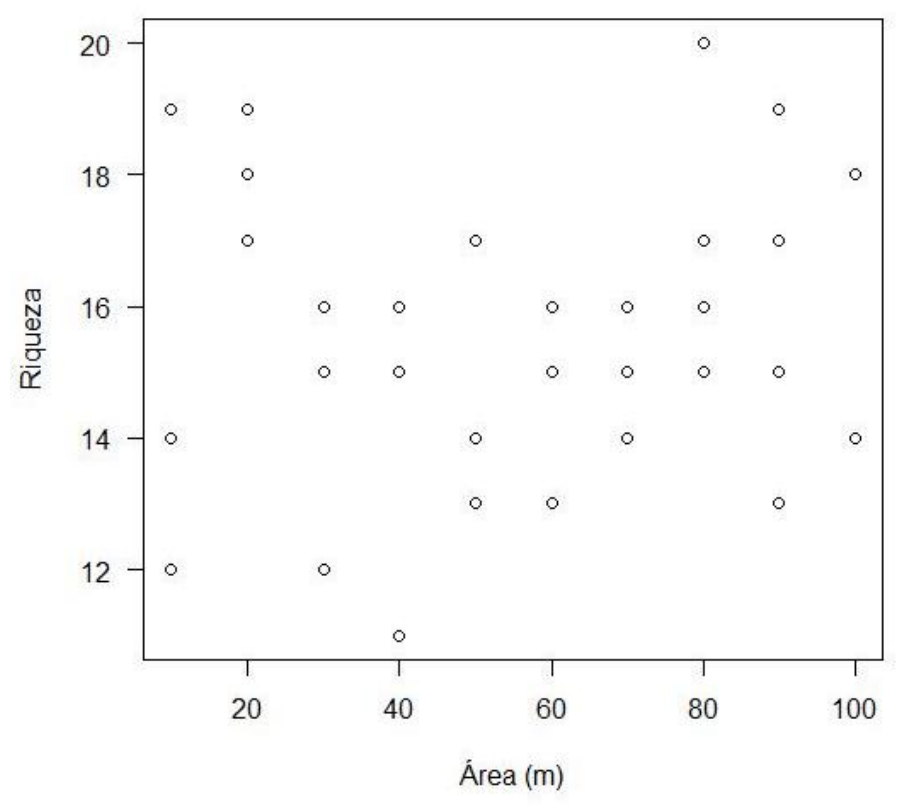

Figura 4. Diagrama de dispersão da riqueza de organismos da macrofauna em relação à área amostral. 
$\mathrm{Na}$ figura 5 encontram-se destacados alguns dos grupos taxonômicos da macrofauna encontrados no fragmento de vegetação da Caatinga da Estação Ecológica Curral do Meio - ESEC.

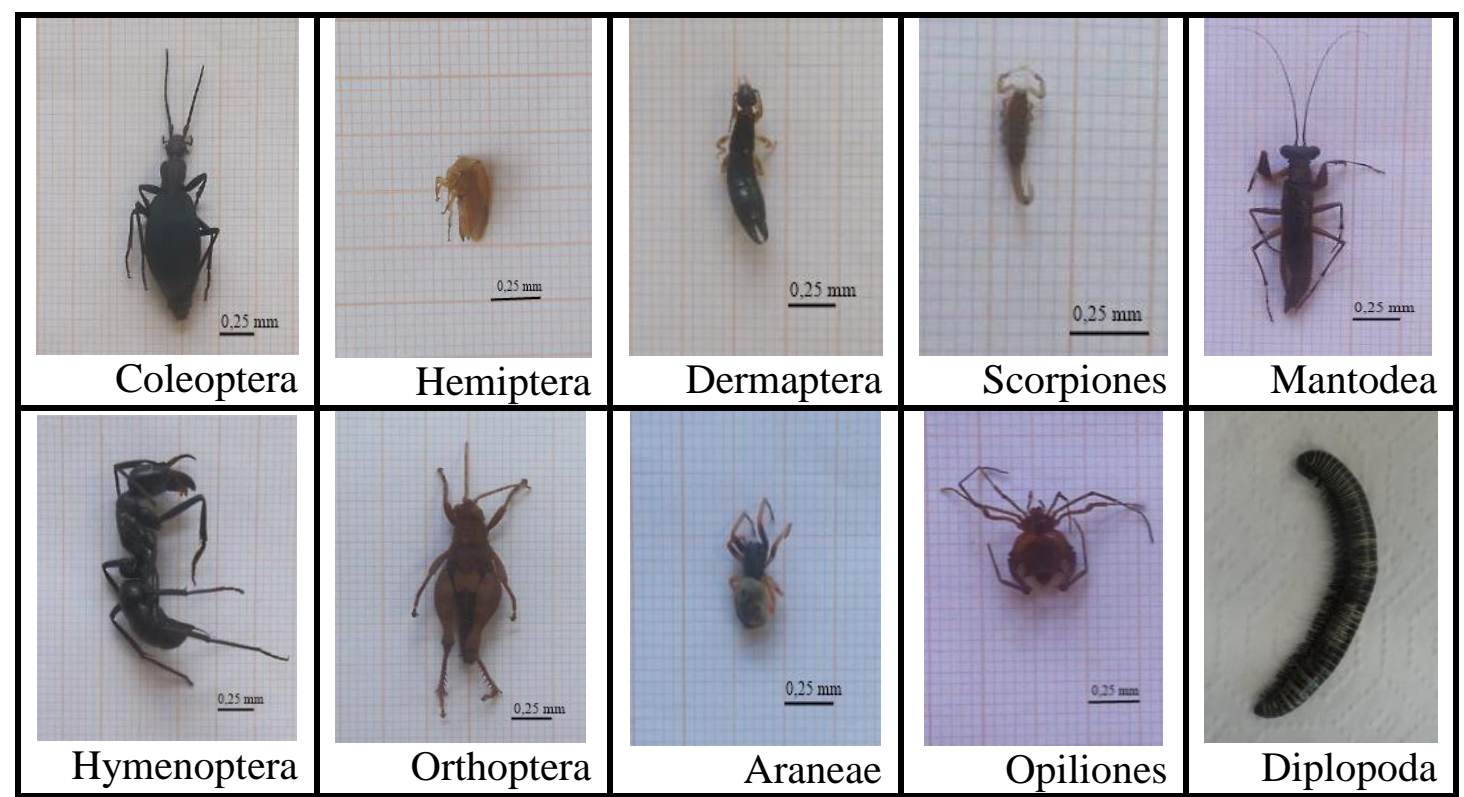

Figura 5. Grupos taxonômicos da macrofauna do solo encontrados na área de Caatinga.

Cada indivíduo e/ou grupo taxonômico desempenha um papel importante nos ecossistemas naturais (ODUM e BARRETT, 2008). Na tabela 3 constam as funções ecológicas de alguns grupos taxonômicos predominantes no solo, encontrados nesta pesquisa. Dos grupos mais abundantes destacam-se Hymenoptera, Coleoptera e Araneae. Machado et al. (2008) mencionam a grande heterogeneidade de modos de vida deste grupo, explicando que estes desempenham papel fundamental na comunidade edáfica. Ainda segundo os autores, as vespas, em grande maioria, são predadoras ou parasitoides e agentes de controle natural das populações, papel desempenhado também por inúmeras espécies de formigas. As vespas e abelhas estão entre os principais polinizadores, sendo responsáveis pela manutenção dos ciclos reprodutivos das plantas, da qual depende a produção de frutos e sementes, bem como a diversidade genética de suas populações.

Tabela 3. Funções ecológicas dos grupos mais comuns da macrofauna do solo

\begin{tabular}{ll}
\hline Nome popular/Ordem/Família & \multicolumn{1}{c}{ Funções ecológicas } \\
\hline Formigas (Formidae) & Predador, Detritívoro, Onívoro, Fitófago, Fungívoro \\
Vespas (Vespidae) & Predador, Parasitoide, Polinizador \\
Abelhas (Apidae) & Polinizador, Dispersor de sementes \\
Besouros (Coleoptera) & Predador, Detritívoro, Onívoro, Fitófago, Rizófago \\
Centopéias (Chilopoda) & Predador \\
Piolhos-de-cobra (Diplopoda) & Detritívoro, Fitófago \\
Cupins (Isoptera) & Detritívoro, Fungívoro, Fitófago, Rizófago, \\
& Humívoro, Xilófago \\
\hline
\end{tabular}




\begin{tabular}{ll}
\hline Cigarrinha (Hemiptera) & Fitófago \\
Garfanhoto, Grilo (Orthoptera) & Detritívoro \\
Tatuzinhos do solo (Isopoda) & Predador \\
Opiliões (Opiliones) & Predador, Detritívoro \\
$\begin{array}{l}\text { Escorpiões (Scorpiones) } \\
\text { Aranhas (Araneae) }\end{array}$ & \\
$\begin{array}{l}\text { Pseudoescorpião (Pseudoescorpiones) } \\
\text { Fase larval (Lepidoptera, Mecoptera, } \\
\text { Diptera, Siphonaptera ou Strepsiptera }\end{array}$ & Detritívoro, Fitófago \\
\hline Adaptado de Triplehorn e Jonnson (2011), Melo et al. (2009) e Machado et al. (2008).
\end{tabular}

Em ambiente de Caatinga, Iannuzzi et al. (2003) estudaram a diversidade de Coleoptera e mencionaram que este é o grupo mais diverso da Classe Insecta, ocupando a maior parte dos ambientes terrestres e adaptado as regiões Áridas e Semiáridas, em virtude de sua modificação morfofisiológica que consiste na abertura dos espiráculos abdominais em um espaço entre o élitro (asas em formas de carapaças) e o abdômen, permitindo que haja a redução da perda de água corpórea.

Há determinados grupos de organismos do solo que se destacam no ambiente florestal por realizar processos chave, a exemplo de Isoptera, Hymenoptera e Coleoptera. Melo et al. (2009) citam que estes destacam-se como detritívoros da serapilheira e do material orgânico, quebrando o material vegetal em frações menores, facilitando a ação decompositora dos microrganismos e agindo na formação e estruturação do solo e ainda, são considerados um grupo funcional denominado de "engenheiros do solo".

O grupo Araneae na maioria dos casos vive em ambientes restritos, como cavernas, ou estão em áreas amplamente impactadas pela urbanização (MACHADO et al., 2008). Este grupo se destaca nos processos ecológicos, pois utilizam o solo e a serapilheira como local de refúgio, reprodução e predação (BATTIROLA et al., 2004).

O sucesso das funções ecológicas desse grupos invertebrados se deve as características físicas e químicas favoráveis que esses ambientes apresentam. As condições edafoclimáticas possibilitam a manutenção da dinâmica da macrofauna, regulando sua atuação no solo e na vegetação. Outros estudos complementares são necessários para compreender-se as demais coorelações invertebrados-solo no ambiente de estudo.

\subsection{Relação entre a macrofauna e os elementos edafoclimáticos}

Houve uma ampla oscilação no número de indivíduos faunísticos entre o período chuvoso e de estiagem (Figura 6). A variação da abundância dos organismos do solo ocorreu pelo fato da área 
experimental ser um ambiente conservado e de elevada riqueza florística, favorecendo o elevado número de indivíduos edáficos.

A abundância de organismos foi maior em dezembro de 2015 (15.819), coincidindo com o período de estiagem da região, atribuído a dominância dos grupos Hymenoptera com 15.423 e Araneae com 267 (Figura 6). O grupo Coleoptera predominou apenas nos meses de abril (1.274), junho (111) e agosto (132) de 2016 (Figura 6). Estes grupos demostraram-se adaptados e predominantes mesmo com estiagem prologada na região durante o período experimental.

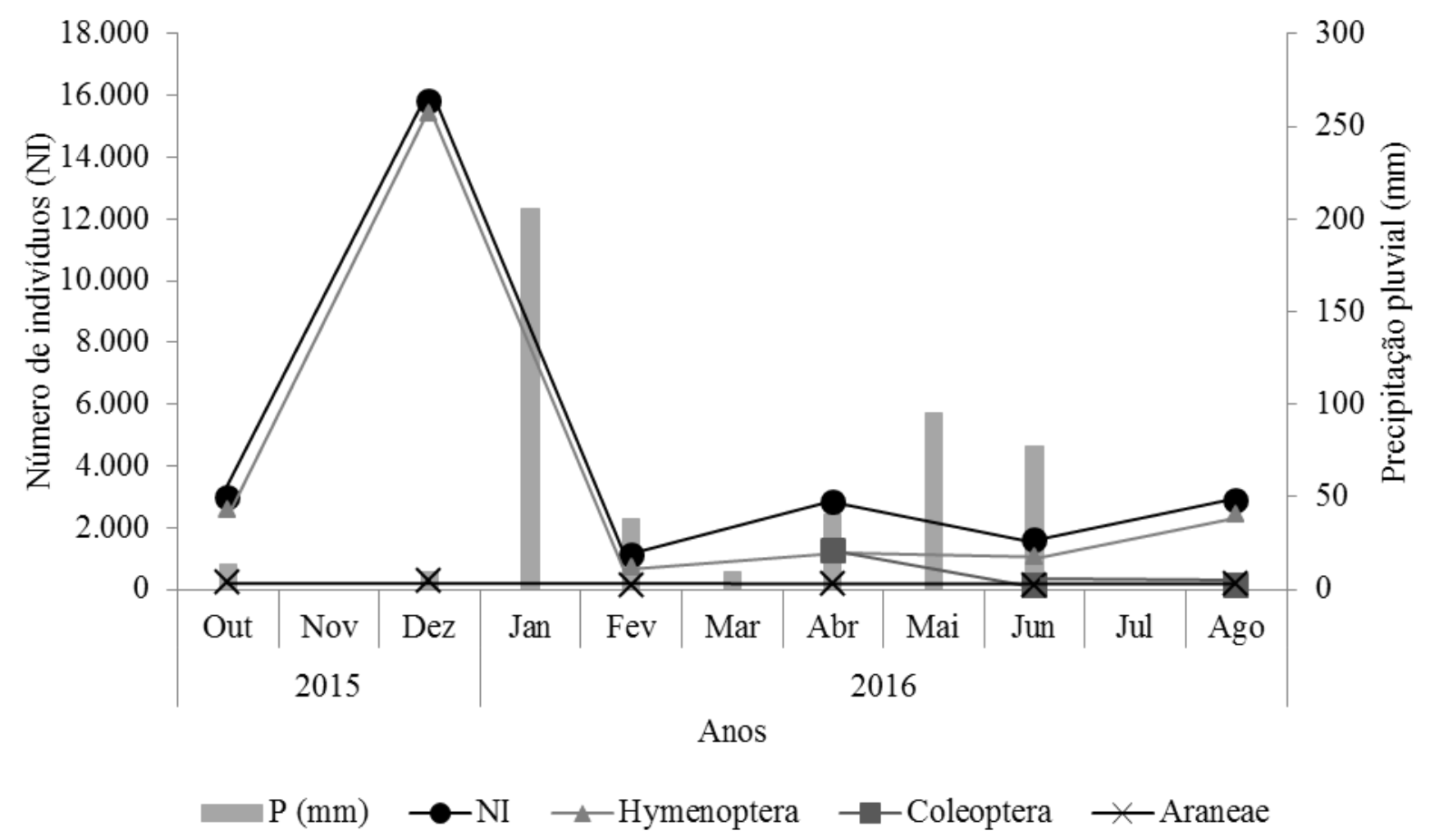

Figura 6. Número de indivíduos (NI) e grupos mais representativos da macrofauna do solo relacionado com Precipitação pluvial (mm).

A riqueza e abundância dos organismos edáficos foi favorecida pelo conteúdo de água do solo mais elevado e temperatura do solo mais amena (Figura 7). Pereira et al. (2012) já haviam constatado em ambiente de mata nativa na Bahia, que a riqueza de grupos taxonômicos é superior no período chuvoso.

Os dados demostraram que há direta correlação com os fatores edafoclimáticos sobre a dinâmica de ocorrência da comunidade do solo, pode-se observar notadamente no mês de dezembro de 2015 , onde a temperaturas do solo foi a mais elevada, chegando a $33,1^{\circ} \mathrm{C}$ e o conteúdo de água do solo foi mais reduzido, 1,13\%, a abundância foi elevada, totalizando-se 15.819 indivíduos e uma pequena riqueza (13 grupos) (Figura 7), confirmando a assertiva de Manhaes e Francelino (2012) que os organismos edáficos são influenciados pelos fatores temperatura, umidade, textura, 
porosidade, dentre outros e a maioria dos organismos preferem ambientes úmidos, assegurado pela presença de argila, que retém conteúdo de água no solo mais elevado.

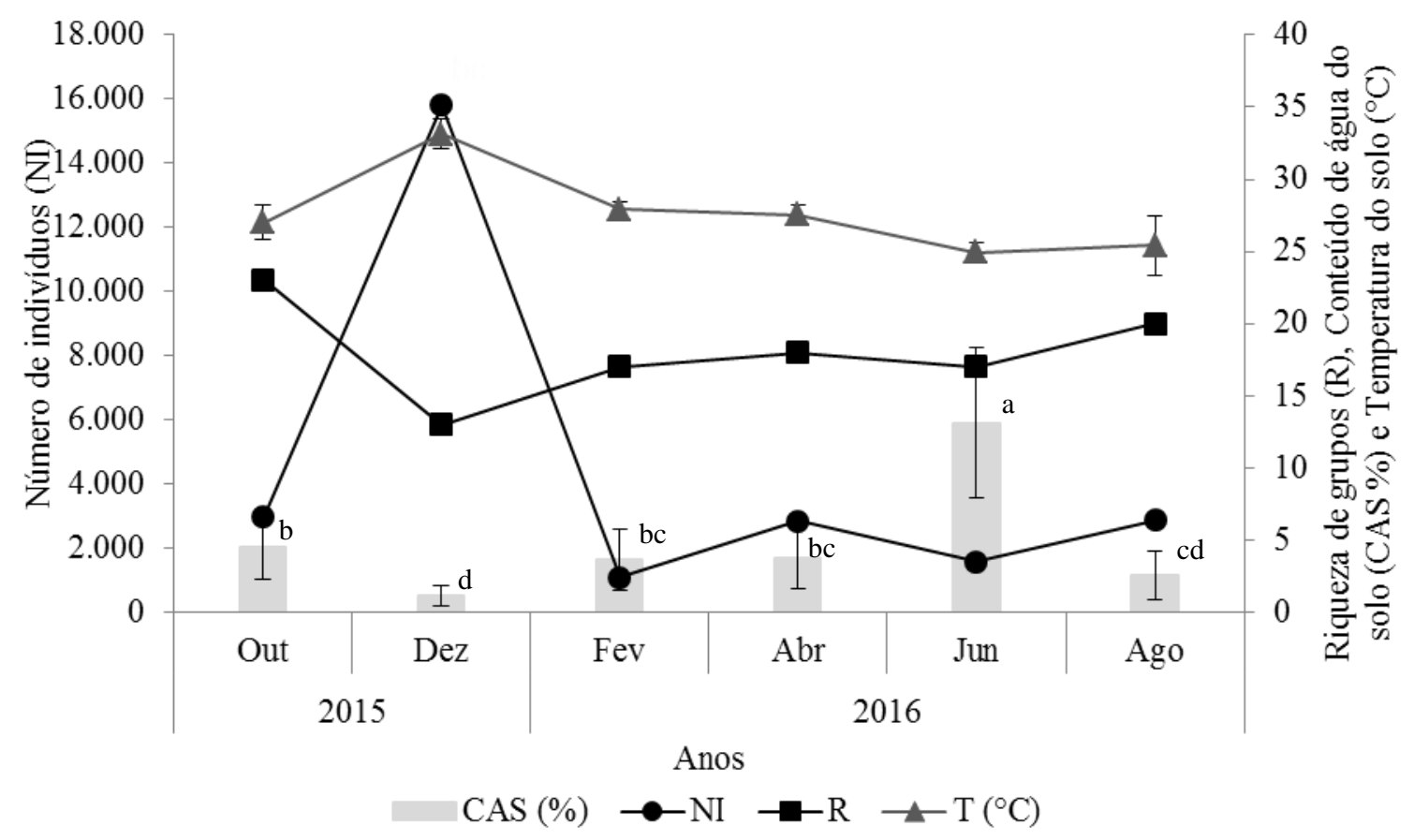

Figura 7. Número de indivíduos da macrofauna do solo (NI), riqueza de grupos (R), relacionado com conteúdo de água do solo $(\mathrm{CAS} \%)$ e temperatura do solo $\left({ }^{\circ} \mathrm{C}\right)$. Barras verticais indicam o desvio padrão. As letras representam a interação entre os meses, pelo Teste de Tukey a $1 \%$ de probabilidade.

$\mathrm{Na}$ área foram observados valores de carbono correspondendo a 47,80 g kg-1 e matéria orgânica do solo de $82,41 \mathrm{~g} \mathrm{kg-}^{1}$, muito acima das condições de outras áreas de Caatinga do Semiárido (Tabela 4), indicando que o ambiente tem um grande aporte de biomassa e um estado de conservação adequado. Os organismos edáficos são os principais atuantes na decomposição de fragmentos vegetais que consequentemente possibilitam que haja o processo de ciclagem de nutrientes do solo neste ambiente. Os valores dessa pesquisa foram elevados, embora Souza et al. (2014) encontraram maiores valores na Caatinga de Olho D’Água do Casado e Delmiro Gouveia em Alagoas evidenciou teores de carbono entre 60 e $80 \mathrm{~g} \mathrm{~kg}^{-1}$ e matéria orgânica variando entre 40 e $120 \mathrm{~g} \mathrm{~kg}^{-1}$.

A diversidade dos grupos faunísticos encontrada na área experimental detentora de altos teores de carbono e matéria orgânica do solo permite aos organismos uma condição adequada para o desenvolvimento de suas funções detritívoras e decompositoras da serapilheira. De acordo com Berude et al. (2015) estes organismos são fundamentais na decomposição de material vegetal, na ciclagem de nutrientes e regulação dos processos biológicos do solo. Pereira et al. (2012) já haviam observado predominância dos organismos da macrofauna nas camadas superficiais da serapilheira e 
do solo, onde ocorrem maior acúmulo de material orgânico. Souto et al. (2009) afirmam que nos ambientes com elevado número de espécies caducifólias, há um potencial elevado de ciclagem de nutrientes por meio da serapilheira, gerando acúmulo de matéria orgânica e carbono.

Tabela 4. Número de indivíduos da macrofauna do solo (NI), riqueza dos grupos $(\mathrm{R})$, carbono $(\mathrm{C})$ e matéria orgânica (MO)

\begin{tabular}{lcccc}
\hline Anos/Meses & $\mathrm{NI}$ & $\mathrm{R}$ & $\mathrm{C}\left(\mathrm{g} \mathrm{kg}^{-1}\right)$ & $\mathrm{MO}\left(\mathrm{g} \mathrm{kg}^{-1}\right)$ \\
\hline Outubro/2015 & 2.967 & 23 & 43,04 & 74,19 \\
Dezembro/2015 & 15.819 & 13 & 44,56 & 76,82 \\
Fevereiro/2016 & 1.087 & 17 & 52,30 & 90,17 \\
Abril/2016 & 2.835 & 18 & 46,63 & 80,39 \\
Junho/2016 & 1.573 & 17 & 44,50 & 76,73 \\
Agosto/2016 & 2.870 & 20 & 55,77 & 96,14 \\
\hline Média & - & - & 47,80 & 82,41 \\
\hline
\end{tabular}

3.4 Índice de diversidade e uniformidade

Em relação aos índices ecológicos, foi constatado que a menor diversidade e uniformidade corresponderam ao grupo Hymenoptera + Larva $(\mathrm{H}=0,07 ; e=0,02)$ (Figuras 8A e 8B), decorrente da elevada abundância dos mesmos (Figuras 8A e 8B). Medeiros et al. (2016) também registraram menores valores dos índices de Shannon $(\mathrm{H})$ e Pielou (e) para o grupo Hymenoptera, comprovando a sua dominância sobre os demais grupos, atribuído a seus hábitos alimentares diversificados e adaptação as temperaturas mais elevadas. Para Townsend et al. (2010) quanto mais marcante é o valor de uniformidade (abundância relativa) maior é o grau de dominância de um grupo.

A raridade de grupos taxonômicos foi para Dermaptera, Diplura, Neuroptera (Larva) e Thysanoptera $(\mathrm{H}=4,43)$ (Figuras 8A e 8B), com apenas 1 indivíduo. Begon et al. (1996) enfatizam que os grupos raros são importantes na dinâmica do ambiente, pois também contribuem no ciclo de decomposição da serapilheira e na cadeia trófica. Triplehorn e Jonnson (2011) destacam que cada grupo apresenta hábitos distintos, escondendo-se em fendas, galerias, rachaduras, sobre cascas de árvores e em resíduos orgânicos. 
A

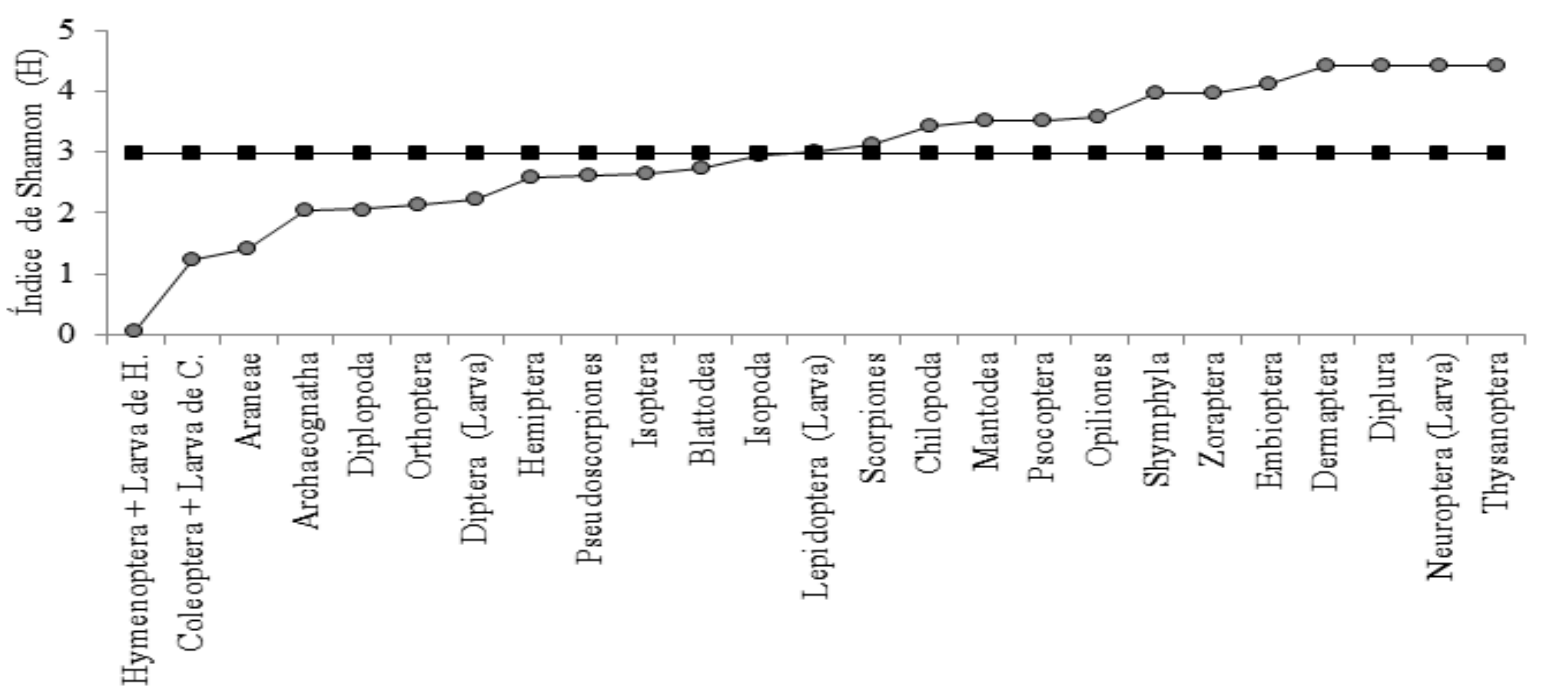

Grupos taxonômicos

B

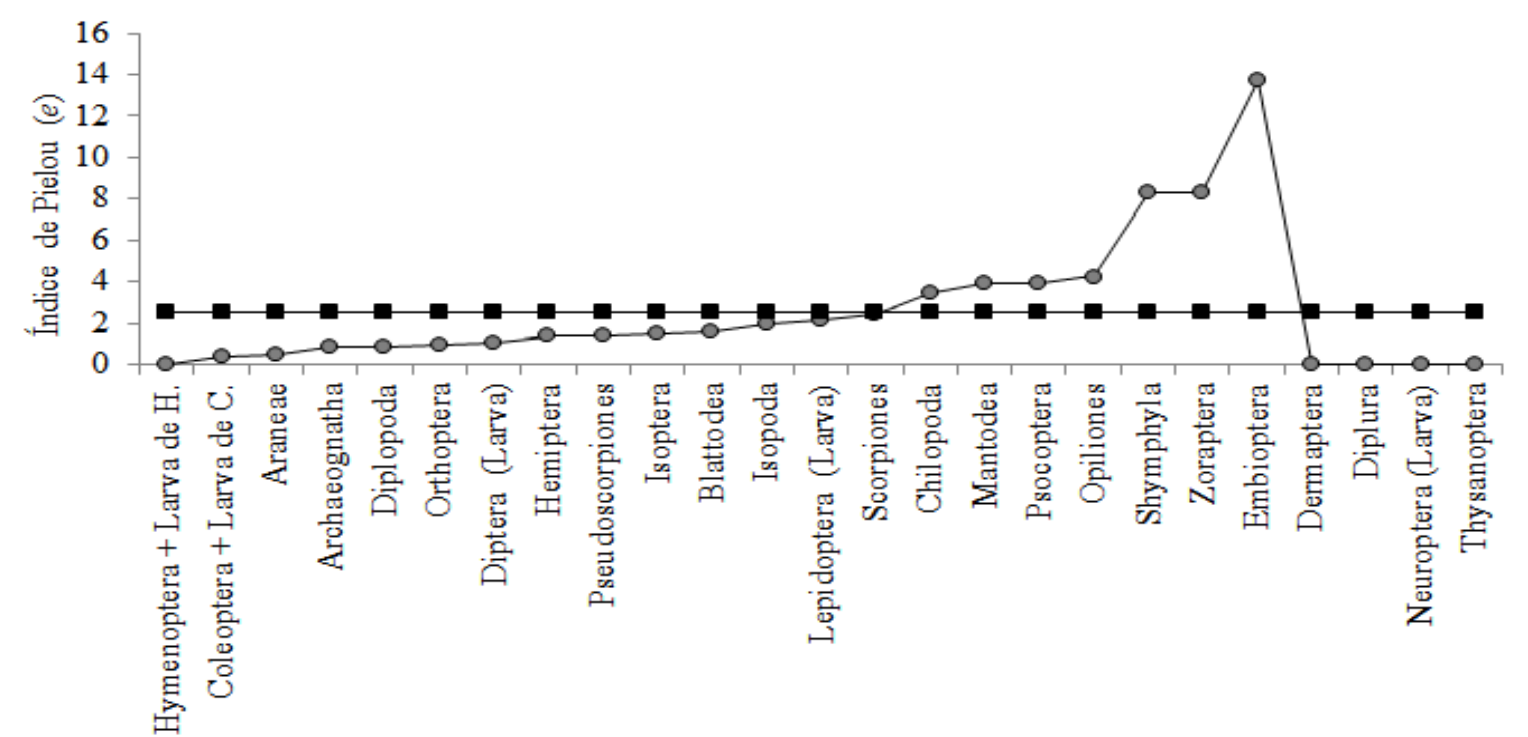

Grupos taxonômicos

$\rightarrow e \rightarrow \overline{e_{\mathrm{x}}}$

Figura 8. Índices de Diversidade de Shannon - H (A) e Equabilidade de Pielou $-e$ (B) dos grupos taxonômicos da macrofauna do solo.

\section{CONCLUSÕES}

O grupo taxonômico mais abundante é Hymenoptera, destacando-se também a ocorrência de Coleoptera e Araneae, comprovados pela menor diversidade e uniformidade;

A maior riqueza dos grupos taxonômicos na área de pesquisa está associada à ampla cobertura vegetal de Caatinga; 
A abundância de indivíduos é maior e a riqueza de grupos e menor quando há temperaturas do solo elevadas e consequentemente menores umidade no solo.

\section{AGRADECIMENTOS}

Os autores agradecem a CAPES/CNPq pelo fomento a bolsa de pesquisa. Ao Laboratório de Solos (CECA/UFAL) e a Embrapa Tabuleiros Costeiros (Unidade Rio Largo/CECA/UFAL) por conceder equipamentos e apoio na realização das análises de solos.

\section{REFERÊNCIAS}

AB'SABER, A. N. Os domínios de natureza no Brasil: potencialidades paisagísticas. 1. ed. São Paulo: Ateliê Editorial, 2003, 151 p.

ALMEIDA, M. A. X. et al. Sazonalidade da macrofauna edáfica do Curimataú da Paraíba, Brasil. Ambiência, Guarapuava, v. 11, n. 2, p. 393-407, jan/abr. 2015.

ALMEIDA, M. A.; SOUTO, J. S.; SOUTO, P. S. Composição e sazonalidade da mesofauna do solo do semiárido paraibano. Revista Verde de Agroecologia e Desenvolvimento Sustentável, Mossoró, v. 8, n. 4, p. 214-222, out/dez. 2013.

ALVES, A. F. L. et al. Caracterização da macro e mesofauna edáfica sobre um fragmento remanescente de "mata atlântica" em Areia-PB. Gaia Scientia, João Pessoa, v. 8, n. 1, p. 384-391, jan/dez. 2014.

ABNT-ASSOCIAÇÃO BRASILEIRA DE NORMAS TÉCNICAS. NBR 6457: Preparação de Amostra de Solo para Ensaio de Compactação e Ensaio de Caracterização. Rio de Janeiro: ABNT, 2016, 1-9 p.

BATTIROLA, L. D. et al. Aspectos ecológicos da comunidade de Araneae (Arthropoda, Arachnida) em copas da palmeira Attalea phalerata Mart. (Arecaceae) no Pantanal de Poconé, Mato Grosso, Brasil. Revista Brasileira de Entomologia, Curitiba, v. 48, n. 3, p. 421-430, set. 2004.

BEGON, M.; TOWNSEND, C. R.; HARPER, J. L. Ecology: individuals, populations and communities. 3. ed. Oxford: Blackwell Science, 1996. 1068 p.

BERUDE, M. C. et al. A mesofauna do solo e sua importância como bioindicadora. Enciclopédia Biosfera, Goiânia, v. 11, n. 22, p. 14-28, jan/dez. 2015.

CRUZ, M. P. et al. Caracterização da macrofauna artrópoda em área de Reserva Florestal no município de Lagoa Seca - Paraíba. Cadernos de Agroecologia, Recife, v. 10, n. 2, p. 1-4, abr/maio. 2015. 
DAMASCENO, J.; SOUTO, J. S. Indicadores biológicos do núcleo de desertificação do Seridó Ocidental da Paraíba. Revista de Geografia, Recife, v. 31, n. 1, p. 100-132, jan/abr. 2014.

DIONÍSIO, J. A. et al. Guia prático de biologia do solo. 1. ed. Curitiba: SBCS/NEPAR, 2016. 152 p.

EMBRAPA-Empresa Brasileira de Pesquisa Agropecuária. Sistema brasileiro de classificação de solos. 4. ed. Brasília: EMBRAPA, 2014. 374 p.

EMBRAPA-Empresa Brasileira de Pesquisa Agropecuária. Zoneamento agroecológico de Alagoas: levantamento de reconhecimento de baixa e média intensidade dos solos do Estado de Alagoas. 1. ed. Recife: EMBRAPA, 2012. 238 p.

EMBRAPA-Empresa Brasileira de Pesquisas Agropecuárias. Manual de análises químicas de solo, plantas e fertilizantes. 2. ed. Rio de Janeiro: Embrapa, 2009. 627 p.

FORNAZIER, R. et al. Modificações na fauna edáfica durante a decomposição da fitomassa de Crotalaria juncea L. In: XXXI CONGRESSO BRASILEIRO DE CIÊNCIA DO SOLO, 31., 2007, Gramado. Anais... Gramado: SBCS, 2007. p. 1-5

GOVERNO DO ESTADO DE ALAGOAS. Anuário estatístico do Estado de Alagoas. 1. ed. Maceió: SEPLANDE, 2011. 457 p.

GULLAN, P. J.; CRANSTON, P. S. Os insetos: um resumo de entomologia. 3. ed. São Paulo: Roca, 2007. 440 p.

IANNUZZI, L. Padrões locais de diversidade de Coleoptera (Insecta) em vegetação de Caatinga. In: LEAL, I. R.; TABARELLI, M.; SILVA, J. M. C. da. Ecologia e conservação da Caatinga. 1. ed. Recife: EDUSPE, 2003. p. 367-390.

LIMA, D. J.; HIGINO, G. T.; VITAL, M. V. C. Coincidência no padrão de riqueza de espécies de vertebrados na mata atlântica: qual o efeito da escala. In: XII CONGRESSO DE ECOLOGIA DO BRASIL, 12., 2015, Belo Horizonte. Anais... Belo Horizonte: UFV, 2015. p. 1-3.

MACHADO, A. B. M. et al. Invertebrados terrestres. In: MACHADO, A. B. M.; DRUMMOND, G. M.; PAGLIA, A. P. Livro vermelho da fauna brasileira ameaçada de extinção. 1. ed. Brasília: MMA, 2008. p. 303-487.

MANHAES, C. M. C.; FRANCELINO, F. M. A. Estudo da inter-relação da qualidade do solo e da serapilheira com a fauna edáfica utilizando análise multivariada. Nucleus, Ituverava, v. 9, n. 2, p. 21-32, out. 2012. 
MARTINS, J. J. A. et al. Estudo da cinética de secagem de folhas de Bauhinia cheilantha (Bong.) Steud. (Mororó). Revista Cubana de Plantas Medicinales, Ciudad de La Habana, v. 20, n. 4, p. 397-408, set/dez. 2015.

MEDEIROS, W. P. et al. Macrofauna do solo em diferentes ambientes no Semiárido da Paraíba. In: IV SEMANA DE ENGENHARIA FLORESTAL DA BAHIA, 4., 2016, Vitória da Conquista. Anais... Vitória da Conquista: UESP, 2016. p. 1-6.

MELO, F. V. de. et al. A importância da meso e macrofauna do solo na fertilidade e como biondicadores. Boletim Informativo da SBCS, Viçosa, v. 39, n. 1, p. 38-43, jan/abr. 2009.

OLIVEIRA, E. M.; SOUTO, J. S. Mesofauna edáfica como indicadora de áreas degradadas. Revista Verde de Agroecologia e Desenvolvimento Sustentável, Mossoró, v. 1, n. 6, p. 1-9, jan/fev. 2011.

ODUM, E. P.; BARRETT, G. W. Fundamentos de ecologia. 5. ed. São Paulo: Cengage Learning, 2008. 612 p.

PEREIRA, R. de C.; ALBANEZ, J. M.; MAMÉDIO, I. M. P. Diversidade da meso e macrofauna edáfica em diferentes sistemas de manejo de uso do solo em Cruz das Almas-BA. Revista Magistra, Cruz das Almas, v. 24, número especial, p. 63-76, dez. 2012.

PINHEIRO, F. J. et al. Caracterização da macrofauna edáfica na interface solo serapilheira em uma área de caatinga do nordeste brasileiro. Enciclopédia biosfera, Goiânia, v. 10, n. 19, p. 2964-2974, jul/dez. 2014.

QUAGGIO, J. A. \& RAIJ, B. V. Comparação de métodos rápidos para a determinação da matéria orgânica em solos. Revista Brasileira de Ciência do Solo, Viçosa, v. 3, n. 1, p. 184-187, jan/fev. 1979.

RAIJ, B. V.; ANDRADE, J. C.; CANTARELLA, H. e QUAGGIO, J. A. Determinação da Matéria Orgânica. In: RAIJ, B. V.; ANDRADE, J. C.; CANTARELLA, H. e QUAGGIO, J. A. Análise química para avaliação da fertilidade de solos tropicais. 1. ed. Campinas: Instituto Agronômico de Campinas, 2001. p.189-199.

ROVEDDER, A. P. et al. Fauna edáfica em solo suscetível à arenização na região sudoeste do Rio Grande do Sul. Revista de Ciências Agroveterinárias, Lages, v. 3, n. 2, p. 87-96, maio/ago. 2004.

SILVA, J.; JUCKSCH, I.; TAVARES, R. C. Invertebrados edáficos em diferentes sistemas de manejo do cafeeiro na Zona da Mata de Minas Gerais. Revista Brasileira de Agroecologia, Pelotas, v. 7, n. 2, p. 112-125, maio/jul. 2012. 
SOUTO, P. C. et al. Características químicas da serapilheira depositada em área de caatinga. Revista Caatinga, Mossoró, v. 22, n. 3, p. 264-272, jan/mar. 2009.

SOUZA, M. H. Macrofauna do solo. Enciclopédia biosfera, Goiânia, v. 11, n. 22, p. 115-131, jul/dez. 2015.

SWIFT, M. J.; HEAL, O. W.; ANDERSON, J. M. Decomposition in terrestrial ecosystems: studies in ecology. 5. ed. Oxford: Blackwell Scientific, 1979. 238 p.

TEDESCO, J. M.; VOLKWEISS, S. J.; BOHNEN, H. Análises do solo, plantas e outros materiais. 1. ed. Porto Alegre: Universidade Federal do Rio Grande do Sul, 1995. 188 p. (Boletim técnico).

TOWNSEND, C. R.; BEGON, M.; HARPER, J. L. Fundamentos em ecologia. 3. ed. Porto Alegre: Artmed, 2010. 576 p.

TRIPLEHORN, C. A.; JONNSON, N. F. Estudo dos insetos. 1. ed. São Paulo: Cengage Learning, 2011. 809 p.

VARGAS, A. B et al. Diversidade de artrópodes da macrofauna edáfica em diferentes usos da terra em Pinheiral, RJ. Acta Scientiae e Technicae, Volta Redonda, v. 1, n. 2, p. 21-27, dez. 2013.

Recebido em: 03/02/2018

Aceito para publicação em: 29/07/2018 